doi 10.7213/comunicao.35.014AO07 e-ISSN 1982-8675 Licenciado sob uma Licença Creative Commons

\section{Comunicação e mobilização política na campanha Fora Ana de Hollanda}

\section{Communication and political mobilization in Fora Ana de Hollanda campaign}

a] Doutora em Sociologia Política pela Universidade Federal de Santa Catarina, professora no Programa de Pós-Graduação em Comunicação da Universidade Federal do Paraná (UFPR), coordenadora do grupo de pesquisa Comunicação e Mobilização Política (CNPq), Curitiba, PR- Brasil, e-mail: kelly.prudencio5@gmail.com

[b] Jornalista, mestrando do Programa de Pós-Graduação em Comunicação na Universidade Federal do Paraná (UFPR), membro do grupo de pesquisa Comunicação e Mobilização Política (CNPq), Curitiba, PR- Brasil, e-mail: weslleydcom@gmail.com

\author{
Kelly Prudencio ${ }^{[a]}$, \\ Weslley Dalcol Leite ${ }^{[b]}$
}

\section{Resumo}

Este artigo é resultado da observação do confronto político evidenciado na campanha Fora Ana de Hollanda no Twitter, uma mobilização que ocorreu em 2011 a partir dos grupos apoiados pelo programa Cultura Viva do Ministério da Cultura - os pontos de cultura - e a gestão da ministra Ana de Hollanda. Orientados pela teoria da mobilização política, mostramos que a mobilização foi organizada pela rede de comunicação preexistente dos pontos de cultura na internet, a qual propiciou a formação de um capital comunicacional aos ativistas; isso Ihes permitiu
Palavras-chave: Comunicação. Mobilização política. Internet. Minc. Ana de Hollanda. 
identificar janelas de oportunidades políticas e criar condições para o confronto. Esse confronto se dá pelos enquadramentos da ação coletiva, entendidos como estratégias de enfrentamento. Para isso, foram analisadas 763 postagens da campanha (\#foraana e \#foranadehollanda) publicadas entre fevereiro e outubro de 2011 no microblog Twitter. A pesquisa identificou que a comunicação na internet funcionou, nesse caso, como fundamento da mobilização, cujo objetivo era manter a política pública, interrompida na gestão da ministra. A campanha campanha apresentou repertório de ações, que, embora não tenha culminado na queda imediata da ministra, colocou a política cultural no centro das discussões daquele período.

\section{Abstract}

This article is the result of an observation of the contentious politics evidenced in the campaign Fora Ana de Hollanda on Twitter, a mobilization that occurred in 2011 from the groups supported by Cultura Viva Program from the Ministry of Culture - the pontos de cultura - and the management of the Minister Ana de Hollanda. Guided by the theory of political mobilization, we show that the mobilization was organized by the preexisting communication network of these pontos de cultura on the internet, which led to the formation of a communicational capital to the activists, allowing them to identify windows of political opportunity and create conditions for confrontation. This confrontation can be seen from the frameworks for collective action, understood as contest strategies. In order to do that, we analyzed 763 posts from the campaign (\#foraana and \#foranadehollanda) published from February to October 2011 in the microblog Twitter. The research identified that communication on the Internet worked in this case as the basis for the mobilization, whose goal was to keep the public police in effect. The campaign presented a repertoire of actions which, although it has not culminated in the immediate downfall of the minister, it placed the cultural politics at the center of discussions of that period.
Keywords: Communication. Political mobilization. Internet. Ministry of Culture of Brazil. Ana de Hollanda. 
O interesse pela mobilização de atores sociais na internet cresce juntamente com a quantidade de protestos, vídeos virais, campanhas, "tuitaços" e outras práticas que se tornam cada vez mais comuns nas chamadas redes sociais. Não é recente o entusiasmo com a internet, uma vez que esse espaço permite que as pessoas se expressem, emitam opiniões e lancem problemas para a discussão. Também há algum tempo, pesquisadores têm mostrado que a participação política não aumenta por causa da internet (RUCHT, 2004; MAIA; GOMES, 2011; PRUDENCIO, 2010). O que se tem percebido são ações coletivas que se valem das características do meio - fácil disponibilização de informação e agilidade de contato, dentre outras - para competir com a agenda da mídia, que não acolhe todas as formas de expressão.

A proposta deste artigo é discutir esse fenômeno a partir do exemplo da campanha Fora Ana de Hollanda, inciada no microblog Twitter no ano de 2011, pela perspectiva da teoria da mobilização política. A teoria considera três aspectos principais: oportunidades políticas, estruturas de mobilização e processos de enquadramento (MCADAM; McCARTHY; ZALD, 2008). O primeiro trata dos momentos de confronto político, quando se tornam visíveis as restrições e oportunidades políticas. O segundo trata de como os atores se organizam para dar conta das oportunidades. E o terceiro se volta para os processos cognitivos de definição de agendas para o debate público. Essa abordagem toma o confronto político como o momento em que se evidenciam os conflitos sociais e cuja discussão passa necessariamente pela mídia, considerada como ator influente no enquadramento das percepções em disputa na esfera pública.

Argumenta-se, ainda, que a mobilização política é precedida pela formação do capital social. Matos (2009) aponta a necessidade da existência de vínculos entre os participantes dos grupos para os encorajarem para a ação coletiva. Como, atualmente, as estratégias de comunicação ganharam centralidade no processo político (GOMES, 2004), ela afirma que a formação de canais comunicativos entre as redes sociais de indivíduos é o principal capital acionado nos protestos, como nas campanhas promovidas na internet.

A mobilização política acontece quando, de forma coletiva, as pessoas fazem reivindicações a outras pessoas cujos interesses seriam afetados se elas fossem atendidas (MCADAM; TARROW; TILLY, 2009). Ao se posicionar diante da sociedade em oposição à gestão ou a ausência de atitudes do campo governamental, os ativistas tornam-se protagonistas desse confronto, e passam a disputar com seus adversários os enquadramentos para o problema (frame constests). 
De acordo com Fligstein e McAdam (2012), um campo de ação estratégica é construído a partir das redes de relacionamentos de agentes que ocupam a mesma posição diante da estrutura política vigente e, além disso, compartilham o mesmo interesse politico, seja na transformação ou na manutenção do status quo.

O campo dos protagonistas, por não ter poder institucional, depende das redes de ativismo construídas a partir da comunicação para realizar a mobilização e, assim, conquistar o poder no confronto político (TARROW, 2009 , p. 237). Dessa forma, consideramos que o conceito de capital comunicacional pode ajudar a compreender a formação e o desenvolvimento da mobilização política.

A partir disso, observa-se, por meio da análise de enquadramento, como a rede de ativismo se mobiliza num processo dinâmico de alterações de estratégias de comunicação. A mobilização política começou em 2011, com rompimento de ações da política governamental, que haviam sido desenvolvidas nas gestões anteriores do Ministério da Cultura (2002-2010). Como resultado, o estudo apresenta as oportunidades políticas que promoveram as mudanças na mobilização política.

Nessa pesquisa foram coletados e analisados 763 tweets com as hashtags $^{1}$ da campanha (\#foraana e \#foranadehollanda) publicados entre fevereiro a outubro de 2011. A metodologia de enquadramento identificou o significado da produção dos ativistas na mobilização, a partir da saliência de temas, de atores (protagonistas e antagonistas do confronto) e repertórios utilizados na construção na ação coletiva pela internet. Os temas mais salientes revelaram referências ao contexto político durante a mobilização, os quais criaram oportunidades políticas. Já a categoria de análise dos atores permitiu reconhecer os ativistas e sua articulação com outros grupos (como o Mobiliza Cultura). O repertório possibilitou identificar as táticas utilizadas pelos ativistas na internet (petição online, blog, compartilhamento de matérias jornalísticas, dentre outros) e seu caráter dinâmico devido às mudanças de oportunidade política.

\section{Enquadramentos da mobilização}

A teoria da mobilização política (MP), que tem sido revisitada nos últimos anos para discutir as novas formas de protesto e ação coletiva,

\footnotetext{
Informações, palavras-chave difundidas nas mídias sociais, geralmente precedidas pelo símbolo "\#", para serem compartilhada com membros da internet por meio de ferramentas como o Twitter.1
} 
oferece alguns elementos importantes para observar a campanha Fora Ana de Hollanda. Uma das razões dessa volta da MP é a ênfase que dá aos processos de significação no confronto político, observável a partir da análise de enquadramento (frame analysis).

O conceito frame, traduzido para enquadramento, é empregado na mobilização política por Snow et al. (1986, p. 464), que os definem como "esquemas interpretativos que permitem aos indivíduos localizar, perceber, identificar e categorizar ocorrências no seu espaço de vida e do mundo em geral". Os enquadramentos produzidos nos campos estratégicos ganham, na análise da mobilização política, uma dimensão social, além da sociopsicológica exposta por Goffman. Segundo Gamson (2011, p. 27), na ação coletiva, os enquadramentos não são apenas atitudes individuais, mas também o resultado da negociação de sentido compartilhado.

Após o processo de enquadramento interno - entre os atores coletivos que compartilham interesse - os campos agem de forma a posicionar seus enquadramentos na esfera pública, a fim de atender às determinadas demandas. Para Tarrow (2009), é possível observar as estratégias de enquadramento a partir dos discursos resultantes do confronto político, que se materializam nos textos, imagens, sons e recursos multimídia, no caso da internet.

Fragoso et al. (2011) discorrem que uma forma de observar a construção de discursos na internet é por meio de sua intensidade. Ao selecionar intencionalmente uma amostra do conteúdo publicado na internet, observa-se quais discursos estiveram mais salientes, tiveram mais repetição a partir dos compartilhamentos dos usuários. Nesta pesquisa, foram coletadas e analisadas todas as publicações (tweets) no Twitter que utilizaram as expressões \#foraana e \#foranadehollanda.

Foi realizado o mapeamento dos usuários que mais compartilharam o conteúdo de protesto; o resultado é uma lista de coletivos que também participaram de um protesto com outra denominação (Mobiliza Cultura), mas cujas demandas iniciais não foram abandonadas. A análise de enquadramento permite visualizar cada um dos momentos da dinâmica do processo de mobilização virtual.

Para identificar a saliência no ciberativismo presente nas mídias sociais, a observação foi feita a partir da quantidade de compartilhamentos de postagens com a mesma temática, destacando-se dois episódios em que a campanha esteve em seu auge, conquistando trending topics ${ }^{2}$ do Twitter.

2 Lista dos assuntos mais comentados por meio do compartilhamento de conteúdo nas mídias sociais. 


\section{O caso Fora Ana de Hollanda}

Em fevereiro de 2011, usuários da internet - especialmente do microblog Twitter - manifestaram sua insatisfação com a gestão do Ministério da Cultura no Brasil (MinC). Com o uso das hashtags \#foraana e \#foranadehollanda, os internautas compartilharam notícias, textos opinativos e comentários expondo os pontos de discordância da política governamental adotada pela ministra Ana Buarque de Hollanda.

O descontentamento dos ativistas com a gestão da ministra teve início após o compartilhamento da ideia de que estava em curso o rompimento de ações que haviam sido desenvolvidas pelas gestões do Ministério da Cultura, no período de 2002 a 2010. Nas primeiras publicações da campanha no Twitter, observa-se que a crítica se dava pela descontinuidade da política de cultura digital - a qual visava a incentivar a produção, distribuição e circulação dos conteúdos culturais com novas tecnologias de informação e comunicação em código aberto. Uma atitude alvo de protesto foi a decisão da ministra pela retirada do selo Creative Commons - que autoriza a distribuição livre do conteúdos do site do MinC.

Os manifestantes também questionaram a retirada da consulta pública que o Ministério da Cultura havia realizado até 2010 para a reforma da lei do direito autoral. A identificação do problema a ser combatido é o enquadramento inicial dos atores insatisfeitos, o qual gera a mobilização ao visualizarem um obstáculo aos seus interesses, constituindo o frame de diagnóstico (SNOW et al., 1986).

Por meio da análise das publicações da campanha no Twitter, observou-se que a maioria das postagens compartilhadas continham hyperlinks, principalmente de blogs de grupos e produtores culturais, denominados "coletivos", cujos textos comentavam ações do Ministério da Cultura.

Em março de 2011, é criado o blog Fora Ana de Hollanda ${ }^{3}$, que descreve a campanha como uma mobilização descentralizada: "O @foraanahollanda não é um 'movimento organizado' é apenas um blog e um perfil no Twitter, cujo objetivo é agregar e difundir as diversas críticas e reflexões sobre a gestão de @anadehollanda no \#minc". Mesmo que o blog afirme que o movimento não integra oficialmente nenhum grupo específico e configura uma ação não oficial da campanha, a página passa a ser um dos principais conteúdos multiplicados por meio do microblog,

3 Disponível em: <http://foraanadehollanda.blogspot.com.br>. Acesso em: 3 ago. 2012. 
principalmente do perfil @foraanadehollanda,cujo criador, que preserva o anonimato, é o mesmo que mantém o blog homônimo.

Com exceção do perfil com o nome da campanha, observou-se, a partir da análise da rede de compartilhamento da campanha ${ }^{4}$, que os multiplicadores dos protestos eram usuários que não eram seguidores apenas no Twitter, mas que formavam outras redes de interesse compartilhado.

Esse primeiro momento da campanha, em que os atores iniciam o confronto, tornando-se protagonistas, foi identificado como o processo de alinhamento de quadros interpretativos (frames). Segundo Snow et al. (1986), essa etapa do confronto é formada por micromobilizações, nas quais os atores já envolvidos buscam o engajamento de seus pares por meio do acionamento do capital social. O foco, nessa fase, é recrutar atores para o confronto e expandir a rede de mobilização.

Em abril de 2011, o número de usuários da mídia social Twitter que utilizam a hashtag \#foraanadehollanda aumentou 223\%. No mesmo mês, a expressão é utilizada juntamente com outra hashtag: \#mobilizacultura. O Mobiliza Cultura, ao contrário da campanha Fora Ana de Hollanda, foi uma mobilização estrategicamente organizada por meio de instituições formais e grupos informais, e que teve organização presencial, além das reuniões virtuais pela internet.

A partir da criação do Mobiliza Cultura, a mobilização anteriormente chamada \#foraanadehollanda, voltada principalmente para a queixa de rompimento da ação cultura digital e da reforma dos direitos autorais sofre novo processo de enquadramento, para se adaptar a esse novo momento, ganhar mais adesão e expansão.

\section{Mobiliza cultura: um novo frame}

A organização do movimento Mobiliza Cultura foi formada por 57 organizações culturais (pontos de cultura, coletivos do circuito de cultura alternativa Fora do Eixo, Fórum Nacional de Música, comunidade Transparência Hacker, dentre outras), além de brasileiros de diferentes localidades não vinculados a entidades do setor, que iniciaram no mês de abril uma articulação para protestar contra a gestão da ministra Ana de Hollanda.

\footnotetext{
4 Análises feitas com o auxílio da ferramenta Topsy (http://topsy.com/). Ressalta-se que a ferramenta não considera publicações privadas e também não contabiliza publicações excluídas pelos usuários.
} 
A primeira reunião presencial foi realizada no dia 25 de abril de 2011, em Brasília. No encontro foram definidas as principais ações realizadas pela rede de organizações. De acordo com a ata da reunião ${ }^{5}$, os pontos de pauta foram a definição conceitual e organização do movimento; a criação de site para o Mobiliza Cultura (Figura 1); a publicação de carta aberta endereçada para a presidente Dilma Rousseff; e a formação de agenda da rede com participação do movimento em atos políticos de diversos fóruns e redes culturais.

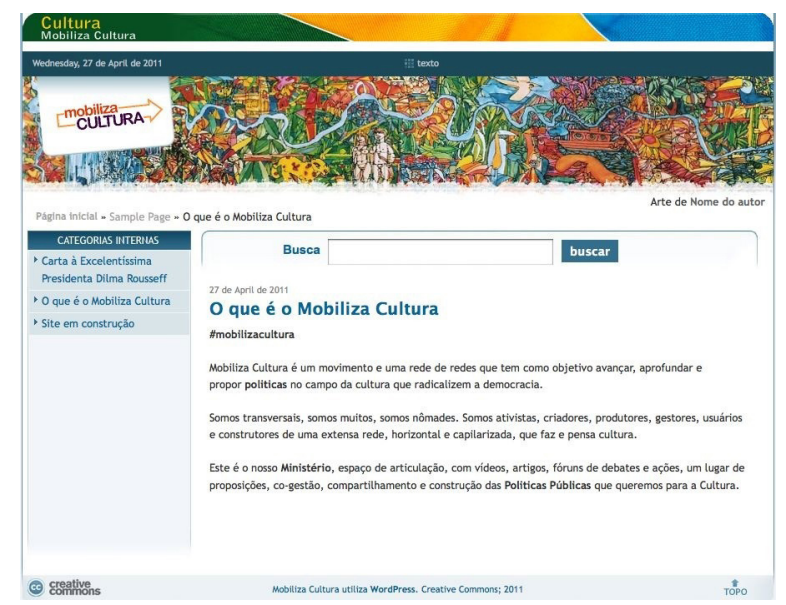

Figura 1 - Página do site Mobiliza Cultura, com a descrição do movimento Fonte: MOBILIZA CULTURA, 2013.

O site Mobiliza Cultura (www.mobilizacultura.org) ${ }^{6}$ foi produzido com o mesmo layout utilizado pelo Ministério da Cultura, para representar que o Ministério é formado pela sociedade civil. No site, havia explicações sobre o movimento, além da reprodução de notícias e artigos opinativos sobre o que se chamou de "crise no Ministério da Cultura". A diferença do site oficial do ministério, além do conteúdo dinâmico e do logotipo, é que na página do Mobiliza Cultura o selo Creative Commons é destacado.

A ação do movimento que teve maior repercussão foi a Carta Aberta à Presidenta Dilma. O documento foi publicado no dia 26 de abril de 2011 e divulgado na imprensa, como nos sites d'O Estadão e d'O Globo,

\footnotetext{
5 Disponível na lista de e-mails do Fórum Nacional de Música: <http://br.groups.yahoo.com/ group/forumnacionaldemusica/message/16034>. Acesso em: 18 ago. 2012.

6 Atualmente, o site não está disponível.
} 
no dia 27 de abril. A carta reivindicava continuidade de políticas culturais adotadas anteriormente no Governo Lula (2002-2010) - cujos ministros da Cultura, Gilberto Gil e Juca Ferreira, promoveram avanços, segundo os signatários da carta. Entre esses signatários estão os grupos pertencentes ao programa Cultura Viva, os pontos de cultura.

O Programa Cultura Viva foi criado em julho de 2004 pelo então ministro da Cultura, Gilberto Gil. Até 2010, a política cultural promoveu a interação de organizações culturais no Brasil, atuantes de diversos segmentos. Entre as ações que promoveram o encontro dos pontos de cultura estão as "teias", encontros nacionais e locais dos pontos de cultura, que aconteceram de 2006 a 2010. Outra ação de encontro promovida pela política são os pontões de cultura, cuja função principal é a articulação de no mínimo dez pontos de cultura. Também no âmbito do programa, foi criada pelo governo a Comissão Nacional dos Pontos de Cultura, cuja finalidade é o fortalecimento da política Cultura Viva, por meio da representação das entidades envolvidas.

Dentre os argumentos utilizados no questionamento da gestão da ministra Ana de Hollanda estão os mesmos apontados na publicação dos usuários da hashtag \#foraanadehollanda anteriormente. Ambas as campanhas reivindicaram: a) participação da sociedade civil para debater a formulação e alteração nas políticas públicas brasileiras, especialmente para a reforma da Lei dos Direitos Culturais; b) aplicação do Plano Nacional de Cultura, aprovado no governo anterior; c) apoio à Cultura Digital - utilização de tecnologias digitais para a democratização cultural; d) continuidade e ampliação do Programa Cultura Viva.

\section{Repertório do confronto e oportunidades políticas}

O processo de enquadramento é dinâmico, pois, ao visualizar mudanças nas relações e nas lógicas dos demais campos, a ação coletiva pode alterar suas interpretações a partir do repertório disponível já construído e das oportunidades políticas. Para Tarrow (2009), toda ação coletiva é marcada pelo confronto político. "O confronto político ocorre quando pessoas comuns, sempre aliadas a cidadãos mais influentes, juntam forças para fazer frente às elites, autoridades e opositores" (TARROW, 2009, p. 18). O que desencadeia o confronto é um arranjo contingente de oportunidades e restrições políticas, que informam os atores sociais em disputa sobre como utilizar repertórios de confronto disponíveis, para, então, ampliá-los e criar inovações pontuais. 
Entendendo (com TILLY, 1992) ${ }^{7}$ o repertório de confronto como um "conjunto limitado de rotinas que são aprendidas, compartilhadas e executadas através de um processo relativamente deliberado de escolha", Tarrow (2009) afirma que ele funciona como um menu de opções disponíveis para a ação, as quais são restritas pelos limites do aprendizado.

As oportunidades para acionar esse repertório aumentam quando o acesso institucional se abre, seja porque há divisões nas elites, seja quando os aliados se tornam disponíveis e quando declina a capacidade de repressão do Estado. Para isso, o processo exige que os desafiantes empreguem repertórios de confronto conhecidos, enquadrem suas mensagens de forma dinâmica e tenham acesso ou construam estruturas de mobilização unificadoras (TARROW, 2009, p. 99).

O conceito de oportunidade política foi desenvolvido por Gamson e Meyer (1996) e se refere às dimensões do ambiente político que estimulam a ação coletiva na medida em que afetam as expectativas das pessoas quanto ao sucesso ou fracasso da ação. Essas dimensões devem ser consistentes - devem oferecer horizontes seguros para a construção da mobilização - , mas não necessariamente formais ou permanentes.

"Se os sistemas políticos institucionalizados moldam as perspectivas para a ação coletiva" (McADAM; McCARTHY; ZALD, 2008, p. 3), as estruturas de mobilização são meios coletivos, formais e informais, pelos quais as pessoas se mobilizam e se engajam em ações coletivas. Dessa forma, o conceito trata de enunciar aquela interação entre atores políticos oriundos de organizações políticas institucionalizadas (Estado, governo, partidos) e as formas de ação política dos demais grupos sociais.

O terceiro fator a observar é o processo de enquadramento. A concepção original de Snow et al. (1986) frisa a dimensão estratégica do enquadramento, que fica mais perceptível quando os atores se deparam com adversários (frame contest). Na disputa de enquadramentos (para legitimar o argumento público) entre atores, o Estado e alguns contramovimentos, o mediador principal é a mídia.

A campanha Fora Ana de Hollanda se apresenta, assim, como um caso de confronto político construído a partir da oportunidade aberta por uma série de acontecimentos. Um deles foi o descontentamento dos beneficiários do programa Cultura Viva - os Pontos de Cultura - com a ameaça de que o financiamento não fosse renovado, pois houve corte de $39 \%$ do

7 TILLY, C. How to detect, describe and explain repertoires of contention. 1992 (texto não publicado, citado por TARROW, 2009, p. 51). 
orçamento do Ministério da Cultura (MinC) em 20118. Outra fonte de confronto que mobilizou grupos de setores culturais foi a retirada do Creative Commons do site do Ministério da Cultura e as denúncias de fraudes do Escritório Central de Arrecadação e Distribuição de Direitos Autorais (Ecad). Surge então a rede Mobiliza Cultura, que aglutina a insatisfação com o MinC e com a ministra e dá novo fôlego à campanha pela sua saída do ministério.

O que parece interessante destacar é que a formação do capital comunicacional pela rede, pelos encontros regionais e nacionais, atualizou e ressignificou o repertório de ação durante a campanha. Ao aproximar atores e propostas tão diversas, o programa Cultura Viva, por meio dos pontos de cultura, havia propiciado a construção de uma linguagem compartilhada, o que, de alguma forma, credenciou os atores para o confronto político.

A campanha no Twitter, com o empenho para entrar e permanecer nas hashtags, configurando o que tem se chamado "tuitaço", torna-se peça de um novo repertório de confronto da ação coletiva contemporânea. Trata-se de uma prática já conhecida e reproduzida por diferentes atores sociais, engajados em diferentes tipos de ação política. A mobilização emplacou dois trend topics (TTs) no Twitter: no dia 3 de maio de 2011, \#minc foi a hashtag mais "tuitada" no Brasil, e no dia 7 de maio, foi o \#foraanadehollanda (Figura 2).

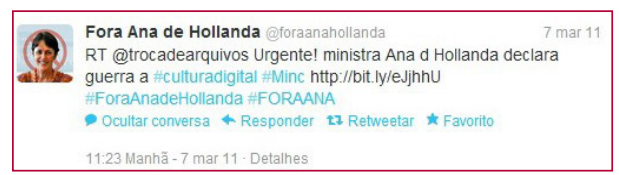

Figura 2 - Um dos primeiros tweets da campanha, protestando contra a política do MinC

Fonte: www.twitter.com

Isso foi possível após denúncias na grande imprensa. Em 1ํ de março de 2011, o jornal O Estado de São Paulo publicou matéria sobre o envolvimento da ministra com o Ecad ${ }^{9}$. Boatos sobre a queda da ministra

8 Disponivel em: <http://www.vermelho.org.br/noticia.php?id_noticia=148981\&id_secao=11>. Acesso em: 11 set. 2011.

9 No dia 1ㅇ de março de 2011, o jornal O Estado de S. Paulo revelou que MinC trocara a direção de Direitos Intelectuais do MinC, colocando Márcia Barbosa, cuja atuação mostrava vínculo com o Escritório Central de Arrecadação e Distribuição de Direitos (Ecad), alvo de nova Lei Autoral. Em 25 de abril, o jornal O Globo revelou que associado do Ecad recebia por trilhas de filmes conhecidos que não eram de sua autoria. 
começam a circular a partir de 4 de maio ${ }^{10}$. No dia 7 de maio, o mesmo jornal noticia o uso de passagens aéreas pela ministra nos fins de semana ${ }^{11}$. Essas notícias são amplamente divulgadas no Twitter e acompanham as hashtags, cujos tweets compartilham também a carta do movimento Mobiliza Cultura ${ }^{12}$ (Figuras 3 e 4).

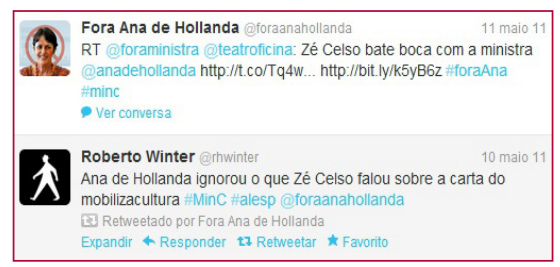

Figura 3 - Tweets com referência à Carta do Mobiliza Cultura

Fonte: www.twitter.com

Fora Ana de Hollanda
Min. @anadehollanda recebe diárias por fins
de semana no Rio (Estadão)
http://va.mu/Csd \#ForaAnadeHollanda
\#LeveGrassiJunto \#Minc @ dilmabr
\& Responder $\mathrm{t}$ Retweetar * Favorito

Figura 4 - Postagem na mídia social Twitter no dia

7 de maio de 2011

Fonte: www.twitter.com

10 Disponível em: <http://www.estadao.com.br/noticias/arteelazer,ministra-na-berlinda,714393,0. htm>. Acesso em: 3 ago. 2012.

${ }^{11}$ Em 7 de maio de 2011, O Estado de S. Paulo revela que a ministra recebe diárias por fins de semana no Rio. De acordo com reportagem do jornal, Ana de Hollanda ganhava ajuda de custo, mesmo tendo imóvel na cidade. O jornal mostrou que, desde que assumiu o cargo, em janeiro, a ministra recebia do governo diárias em fins de semana sem compromissos oficiais no Rio e onde possui imóvel próprio. Disponível em: <http://www.estadao.com.br/noticias/nacional,ministrarecebe-diarias-por-fins-de-semana-no-rio,716236,0.htm>. Acesso em: 3 ago. 2012.

12 Disponível em:<http://www.redebrasilatual.com.br/temas/entretenimento/2011/05/aumentapressao-pela-saida-de-ana-de-hollanda-do-ministerio-da-cultura>. Acesso em: 3 ago. 2012. <http://www.muco.com.br/index.php?option=com_content\&view=article\&id=525: escanda lo-no-ministerio-da-cultura-ou-ana-de-hollanda\&catid=34:sala-de-escandalos\&|temid=53>. Acesso em: 3 ago. 2012. 
A construção desse novo repertório se dá pela oferta de quadros interpretativos (frames) para a ação. Há nesse processo um esforço de uniformização para uma mensagem múltipla e complexa. Segundo Tarrow (2009), os símbolos culturais não estão automaticamente disponíveis como símbolos mobilizadores, mas exigem agentes concretos para transformá-los em frames de confronto. É a combinação de novos quadros interpretativos inseridos numa matriz cultural que produz quadros interpretativos com alguma força de mobilização.

O que se percebeu na campanha Fora Ana de Hollanda é que houve uma mudança nos quadros interpretativos à medida que os acontecimentos exigiam um novo posicionamento. Inicialmente, a campanha foi motivada pela condução insatisfatória, na visão dos opositores, do programa Cultura Viva pelo MinC. A ministra era criticada por não manter as políticas culturais iniciadas nas gestões anteriores, assim como era acusada de não manter diálogo com setores populares. Com as denúncias do jornal $O$ Estado de São Paulo, houve um redirecionamento do quadro interpretativo; de uma questão de incompetência na gestão classificando-a como "desastre" - passou-se a falar em conduta incompativel, envolvimento com o Ecad, imprimindo um tom de denúncia com o "escândalo" do uso do dinheiro público para fins pessoais.

\section{Capital comunicacional como recurso}

O movimento Mobiliza Cultura utilizou estratégias de comunicação como reuniões presenciais e virtuais; preocupou-se com a identidade do movimento, sua marca através do logotipo e do site; além de envio de material (carta) para imprensa, amplamente divulgado através dos sites, blogs e perfis em mídias sociais de grupos culturais e produtores brasileiros.

O Fora Ana de Hollanda, enquanto uma campanha na internet já existia anteriormente à formalização do Mobiliza Cultura. No entanto, embora não tenha havido uma estratégia formalizada para a utilização das hashtag \#foraana ou \#foraanadehollanda, ela foi imediatamente sendo reproduzida juntamente com o compartilhamento das notícias do Mobiliza Cultura, principalmente com a Carta Aberta.

É nesse encontro entre uma campanha dispersa e desorganizada, com um movimento organizado e, de início, centralizado, que a expressão passa a ser viral na internet. É por não congregar redes sociais densas, além da diversificação de identidades políticas que se unem no confronto a uma 
causa específica, é que muitas ações coletivas da atualidade têm sido chamadas de redes de mobilização social (SCHERER-WARREN, 2005).

As redes de ativismo tem sua base na comunicação e na busca por visibilidade para conquistar o poder no confronto político (KECK; SIKKINK ${ }^{13}$ apud TARROW, 2009, p. 237). Maria da Glória Gohn (2010) reconhece que as representações simbólicas a partir da comunicação são uma das características da mobilização política contemporânea, as quais se estruturam em redes sociais já existentes, mas fazem encontros com outras redes para ganhar adesão, visibilidade ou oportunidade.

As redes sociais articuladas para o ativismo político constroem laços sociais a partir da cooperação e do compartilhamento de significados. Na ação coletiva, interesses privados não são abandonados, mas podem se reconfigurar para conquistar os objetivos através da ação coletiva. No coletivo, os participantes da rede se unem pelo engajamento e constroem estratégias próprias de ação para a mobilização. Ao conjunto de recursos formados nas redes sociais, tais como as táticas utilizadas e os vínculos formados, é denominado "capital social", o qual possibilita o desenvolvimento de ações com outros grupos para seu crescimento e para o confronto político (MATOS, 2009, p. 33-41).

Na campanha analisada observou-se que a ação utilizada foi a comunicação para a divulgação pública de uma reinvindicação. De acordo com Matos (2009, p. 210), o capital comunicacional compõe o capital social e, atualmente, é um dos principais recursos utilizados para mobilizar indivíduos.

O capital comunicacional pode ser definido por padrões de redes sociais. As interações comunicativas que se estabelecem entre diferentes setores e grupos da sociedade organizada tendem a gerar redes e fluxos de informações que se expandem para públicos cada vez mais amplos. Os processos de articulação dos indivíduos em redes potencializam não só as oportunidades de aprofundamento reflexivo de conversações informais, mas também alimentam práticas cívicas e participativas, colaborando para um aumento das trocas e debates críticos entre diferentes grupos sociais.

O fluxo de comunicação na campanha Fora Ana de Hollanda ocorreu com a utilização de canais construídos, como nos perfis do Twitter

${ }^{13}$ KECK, M. E.; SIKKINK, K. Transnational issue networks in international politics. (Apresentado na Annual Conference of the American Political Science Association, Chicago, 1995). 
e blogs de grupos com vínculos mais densos (por terem ações também presenciais e reconhecimento pelo trabalho cultural), como a Rede Cultura Digital, os Pontos de Cultura, o circuito Fora do Eixo e, principalmente, a rede formada pelo movimento Mobiliza Cultura. Com alteração de enquadramento, a repercussão da campanha teve mais visibilidade e propiciou a repercussão da hashtag \#foraanadehollanda para grupos que não estavam envolvidos na discussão e, depois, com a oportunidade política, ganhou notoriedade como assunto mais comentado na mídia social (trend topics).

\section{Considerações finais}

A campanha Fora Ana de Hollanda moldou-se de acordo com as oportunidades políticas que se apresentaram. O movimento político realizado em 2011 pelas organizações em rede não teve interesse em alterar radicalmente o sistema econômico ou político vigente. Os grupos culturais buscaram a manutenção das políticas adotadas pela gestão do MinC nos anos anteriores (2002-2010) e tiveram como alvo principal o governo.

O processo de formação da mobilização se deu fundamentalmente por meio da comunicação. As interações ocorreram de forma presencial, com a reunião de uma rede de organizações e produtores culturais, e também teve repercussão entre redes formadas anteriormente, como a Comissão Nacional dos Pontos de Cultura. Também ocorreram de forma virtual, com discussões nos grupos de e-mail, como na lista do Fórum Nacional de Música, nas listas de Pontos de Cultura e outros grupos culturais regionais e locais, além das reuniões virtuais do Mobiliza Cultura.

Com os encontros presenciais, os grupos criaram confiança mútua e construíram identidades coletivas, que se estenderam, por meio das novas tecnologias, para seu desenvolvimento e continuidade, caracterizando o que Matos (2009) chama de "capital comunicacional", acionado na contingência do confronto político.

Os momentos propícios para emplacar os enquadramentos ocorreram quando o adversário, a gestão da ministra, esteve em visibilidade por algum discurso ou ato polêmico, principalmente através das mídias sociais. Ana de Hollanda foi a primeira a sofrer a pressão para deixar o ministério no primeiro ano do governo Dilma Roussef. Na sequência, sete ministros foram demitidos pela presidenta por suspeitas de corrupção. 
Ana de Hollanda não estava entre eles ${ }^{14}$. Embora a campanha pressionasse claramente pela sua saída, esse objetivo não foi alcançado. Isso pode levar a considerar que a campanha no Twitter não obteve êxito.

No entanto, se for observada a trajetória da mobilização, o quadro pode ser favorável aos opositores. A campanha se desenvolve a partir de uma ação contida no repertório atual de confronto: emplacam duas hashtags no Twitter. Figurar nos TTs não era a meta da campanha, mas uma performance com vistas à mobilização do consenso. Para isso, era preciso desenhar o quadro interpretativo da questão, localizá-lo na ministra e estabelecer o confronto. A hastag \#foraanadehollanda teve notoriedade porque utilizou o capital comunicacional e as redes já articuladas nos atos anteriores. O ativismo se caracteriza como redes de mobilização, pois conseguiu aproveitar também relações preexistentes com outros movimentos, organizações e fóruns para a ampliação dos públicos e ganhar visibilidade.

As denúncias contra a ministra funcionaram como oportunidade política para o crescimento da campanha, que passou a contar com a força do movimento Mobiliza Cultura, o que reposicionou os quadros interpretativos. O estudo da campanha mostra que a mobilização política não se encerra na conversa que se estabelece no Twitter. Embora ela tenha obtido visibilidade no microblog, foi o conjunto de ações dos grupos que compunham a rede de mobilização que conseguiu articulá-la. O que se pode afirmar é que o processo de mobilização é fundamentalmente um processo de comunicação, no qual os atores - em um processo de dinâmico de enquadramento - falam e respondem, orientam e redirecionam suas ações. O Twitter, nesse caso, não sustentou sozinho a campanha, mas essa não teria a força mobilizadora que teve sem o apoio da ferramenta.

\section{Referências}

FLIGSTEIN, N.; MCADAM, D. A theory of fields. Oxford; New York: Oxford University Press, 2012.

\footnotetext{
14 A ministra foi demitida no dia 11 de setembro de 2012, tendo sido substituída pela senadora Marta Suplicy. Disponível em: <http://noticias.uol.com.br/politica/ultimasnoticias/2012/09/11/apos-serie-de-desgastes-ana-de-hollanda-deixa-ministerio-da-cultura. htm>. Acesso em: 11 ago. 2013.
} 
FRAGOSO, S.; RECUERO, R.; AMARAL, A. Métodos de pesquisa para internet. Porto Alegre: Sulina, 2011.

GAMSON, W. Falando de Política. Belo Horizonte: Autêntica Editora, 2011.

GAMSON, W.; MEYER, D. Framing of political opportunity. McADAM, D.; McCARTHY, J. D.; ZALD, M. N. (orgs). Comparative perspectives on social movements: political opportunities, mobilizing structures, and cultural framings. Cambridge: Cambridge University Press, 1996. p. 275-290.

GOFFMAN, E. Os quadros da experiência social: uma perspectiva de análise. Petrópolis: Vozes, 2012.

GOHN, M. G. Teorias dos movimentos sociais: paradigmas clássicos e contemporâneos. São Paulo: Loyola, 2011.

GOHN, M. G. Movimentos sociais e redes de mobilizações no Brasil contemporâneo. Petrópolis: Vozes, 2010. v. 1.

GOMES, W. Transformações da política na era da comunicação de massa. São Paulo: Paulus, 2004.

MAIA, R.; GOMES, W.; MARQUES, F. P. J. (Org.). Internet e participação política no Brasil. Porto Alegre: Sulina, 2011.

MATOS, H. Capital social e comunicação: interfaces e articulações. São Paulo: Summus, 2009.

MCADAM, D.; TARROW, S.; TILLY, C. Para mapear o confronto político. Lua Nova, n. 76, p. 11-48, 2009.

MCADAM, D.; McCARTHY, J.; ZALD, M. (Ed). Comparative perspectives on social movements: political opportunities, mobilizing structures and cultural framings. Cambridge: Cambridge University Press, 2008.

MOBILIZA CULTURA. Disponível em: <www.mobilizacultura.org >. Acesso em: 2 ago. 2013.

PRUDENCIO, K. Mobilizar a opinião pública: sobre a comunicação dos ativistas políticos. In: MIGUEL, L. F.; BIROLI, F. (Org). Mídia, representação e democracia. São Paulo: Hucitec, 2010.

RUCHT, D. The quadruple 'A': media strategies of protest movements since the 1960s. In: VAN DE DONK, W. et al. Cyberprotest: new media, citizens and social movements. London: Routledge, 2004. 
PRUDENCIO, K.; LEITE, W. D.

SCHERER-WARREN, I. Das mobilizações às redes de movimentos sociais. Sociedade e Estado, v. 21, n. 1, p. 109-130, jan./abr. 2006.

SNOW, D. et al. Frame alignment and mobilization. American Sociological Review, n. 51, p. 464-481, 1986.

TARROW, S. Poder em movimento: movimentos sociais e confronto político. Petrópolis: Vozes, 2009.

Recebido: 02/09/2013

Received: 09/02/2013

Aprovado: $21 / 10 / 2013$

Approved: 10/21/2013 